\title{
Reflexões de um Internista e Intensivista em Tempos de Pandemia pelo SARS CoV-2
}

\author{
An Internist and Intensivist Reflections in Times of SARS COV-2 \\ Pandemic
}

\author{
António H. Carneiro (https://orcid.org/0000-0002-0774-6863)
}

\section{Resumo:}

A pandemia pelo SARS CoV-2 (systemic acute respiratory syndrome - Coronavírus 2) espalhou-se por todo o mundo a uma velocidade inusitada. Em vários países provocou infeções graves e simultâneas em tão elevado número que levou à rotura dos sistemas de saúde. Há mais dúvidas do que certezas sobre a fisiopatologia da doença e do seu tratamento, mas já é claro que é uma doença sistémica, que se inicia mais frequentemente por sintomas respiratórios. Não tem tratamento etiológico conhecido e o tratamento de suporte nos casos mais graves é menos eficaz do que o esperado, a requerer estratégias diferentes do que as conhecíamos até aqui. As atitudes mais eficazes, até agora, são as mesmas que eram recomendadas na idade média: distanciamento social, prevenção de contactos e confinamento. A pandemia vulnerabiliza a humanidade no seu todo, "justifica" restrições massivas à circulação e às liberdades, precipita uma crise económica de proporções ainda desconhecidas e ninguém sabe o que acontecerá no futuro, aos sobreviventes e à possibilidade de recirculação do vírus. É tempo de refletirmos. A organização da sociedade vai mudar e nós seremos protagonistas.

Palavras-chave: Coronavírus; Pandemia.

\section{Abstract:}

SARS CoV-2 (systemic acute respiratory syndrome - virus 2) pandemic spread around the world at an unusual rate. In some countries, it has caused serious and simultaneous infections, in such a large number that several health systems disrupted. There are more doubts than certainties about its pathophysiology and treatment, but it is already clear that it is a systemic disease, which is initiated more often by respiratory symptoms No etiological treatment is known. Supportive treatment in the most severe cases is less effective than expected, requiring different strategies than we knew so far. The most effective attitudes so far are those that were

Chefe de Serviço de Medicina Interna, Diretor do Departamento de Medicina, Urgência e UCI, Hospital da Luz - Arrábida, Vila Nova de Gaia, Portugal

https://revista.spmi.pt - DOI: 10.24950/rspmi/P.Vista/COVID19/ A.H.Carneiro/HLA/S/2020 recommended in the middle ages: social distancing, prevention of contacts and confinement. The pandemic makes humanity vulnerable as a whole, "justifies" massive restrictions on circulation and freedoms, precipitates an economic crisis of unknown proportions. No one knows what will happen in the future, to the survivors and to the possibility of recirculation of the virus. It is time to reflect the human condition and human relations. Society organization will change, and we will be protagonists.

Keywords: Coronavirus; Pandemics.

\section{O problema}

A pandemia pelo SARS CoV-2 (COVID-19 - Coronavírus 19) surpreendeu o mundo, alterou comportamentos, provocou roturas nas instituições de inúmeros países e desafia a organização futura das nossas sociedades. Estamos na fase do embate com uma realidade nova, estamos a tentar compreender o que aconteceu, estamos a preparar o devir na expectativa do que vai acontecer. Enquanto não existir uma vacina eficaz para o COVID-19 o quotidiano continuará marcado, pelo risco de contágio, pela incerteza e pela necessidade de reajustar as relações pessoais, profissionais e sociais. Teremos de encontrar modelos de relação humana, de organização social e de trabalho que possam ser vividos como um "novo normal". Esse "novo normal" será construído a partir do presente, dos seus constrangimentos e do que formos capazes de aprender com o conhecimento e com a experiência.

\section{Esta pandemia é uma surpresa ou é uma ocorrência antecipável?}

Bill Gates em 2015 proferiu uma Ted Talk' intitulada "...A próxima epidemia? não estamos preparados..." na qual antecipou, ponto por ponto, com um realismo surpreendente tudo o que aconteceu com o SARS CoV-2, desde a origem à disseminação global. O seu alerta alicerçou-se no conhecimento científico e nas experiências prévias com a gripe sazonal, SARS 1, H1N1, MERS, ZICA, Ébola, ... e todas as restantes epidemias e pandemias ${ }^{1,2}$ que as precederam e concluiu "...não estamos preparados...”. É seguro e certo que não estávamos.

Bill Gates não é adivinho. Foi assessorado por peritos em epidemiologia associados à Fundação Melinda e Bill Gates, 
olhou com objetividade para os dados históricos e foi porta-voz do que a ciência antecipava como possibilidade no domínio da ocorrência de novas pandemias. ${ }^{1}$

A humanidade sempre se confrontou com epidemias e pandemias. Estima-se que a peste bubónica (1347-51 DC) tenha causado 200 milhões de mortos e que a chamada "gripe espanhola" (1918-9 DC) tenha ceifado 40-50 milhões de vidas. ${ }^{3}$ Números felizmente longe da experiência que agora vivemos. Como sustenta $\mathrm{M}^{\mathrm{a}}$ Manuel Mota (entrevista ao Expresso publicada em 2020 abril 18) este vírus tem uma taxa de mortalidade inferior à dos seus predecessores. Todos os anos há acréscimo de mortalidade, em particular dos mais vulneráveis, na altura em que a epidemia de gripe é mais agressiva. A diferença é que desta vez a dimensão do contágio e a mortalidade associada expuseram a vulnerabilidade da humanidade como um todo. Confrontamo-nos com questões novas e com outras antigas, mas com as quais não fomos capazes de aprender o suficiente para aguentar este embate..$^{2,3}$

Os humanos viajam por todo o mundo, mais do que alguma vez o fizeram. Esse modo de vida expõe-nos a ambientes para os quais não desenvolveram defesas, provocam contactos com modos de vida desconhecidos e permite-lhes dispersar, contaminantes / infetantes contraídos longe do domicílio habitual, à mesma velocidade com que se deslocam.

O COVID-19 dispersou-se por todo o mundo em três meses.

Não somos capazes de aprender com o passado? Ou somos, mas os valores dominantes ofuscam o bem comum em benefício do lucro, encandeados como estão com as conquistas insaciáveis da tecnologia, ela própria escrava do seu próprio sucesso a qualquer preço.

\section{Somos vulneráveis}

É provável que o pânico inoculado pelas redes sociais e as manchetes jornalísticas tenham empolado, em parte, o problema. Mas a pandemia existe e a sua mortalidade é real.

O COVID-19 é altamente contagioso, dissemina-se por gotículas que se dispersam por via aérea, depositam-se em superfícies onde persiste por horas, mantendo o potencial infetante. Mais de $80 \%$ dos infetados mantêm-se em ambulatório, na maioria assintomáticos, mas com elevado potencial infetante, como Bill Gates antecipou na sua simulação de 2015. ${ }^{1}$

Apesar de, neste caso, a mortalidade ser menor da que se associa ao SARS 1 ou ao MERS (vírus similares) o COVID-19 é mortal para um número significativo de pessoas em particular os mais velhos e os portadores de comorbilidades (como acontece com outros vírus respiratórios). ${ }^{4}$ Mas desta vez essas mortes não ocorrem lá longe, na terra dos outros, ocorrem ao nosso lado, com os nossos conhecidos e familiares. Alguns de nós somos ou podemos ser infetados e não há tratamento conhecido que elimine o micróbio. A ocorrência de inúmeros casos em simultâneo sobrecarregou de tal maneira os sistemas de saúde que alguns deles entraram em rotura. Países
Europeus e Norte-Americanos que se julgavam protegidos por serviços de saúde diferenciados sucumbiram ao progresso rápido e massivo da pandemia. ${ }^{4,5}$

Neste contexto percebemos que os tratamentos eficazes são distanciamento, a prevenção de contactos infetantes e o confinamento. Nenhum deles se vende nas farmácias, mas todos desafiam a liberdade de circulação, o nosso modo de vida e as relações incluindo o modo de subsistência de muitos de nós.

Percebemos de repente quão vulneráveis somos. Descobrimos de repente que todos somos "suscetíveis de sermos feridos ("vulnus = ferida")". O vírus não olha a títulos nobiliárquicos, nem a funções governativas, nem a estatutos sociais, .... Trata-nos a todos por igual quando não respeitarmos as regras de contenção. As defesas comprovadamente eficazes têm séculos.

\section{O medo, ... resistir}

Estes momentos de tensão e ameaça à sobrevivência revelam o que de mais profundo habita as pessoas, que vive camuflado pelas imagens construídas pelas posturas do "basta parecer", não é preciso "ser" (tão cultivada em algumas redes sociais). O melhor e o pior de cada um vem mais facilmente à superfície e mostra-se sem máscaras e sem maquiagem, quando todos ficam em risco. É nestes momentos que "... O vírus da indiferença egoísta...", como the chama o Papa Francisco, ${ }^{6}$ tem maior probabilidade de despertar. É um vírus que se "...transmite a partir da ideia de que a vida melhora se for melhor para mim, que tudo corre bem se correr melhor para mim, para daqui se chegar à ideia da seleção e da discriminação das pessoas...". ${ }^{6}$

A demagogia egocêntrica chega a assumir dimensões repugnantes, quer ao nível de algumas opções políticas quer no comportamento de pessoas capazes de ameaçar profissionais de saúde, seus vizinhos, por trabalharem em hospitais que tratam doentes infetados. O estigma da peste está de volta. As pessoas revelam-se verdadeiramente nas crises. Há revelações no comportamento humano e social, que muitos não conheciam nem imaginavam possível, mas que, em poucas semanas, descobrimos com estrondo.

Os profetas da desgraça e os abutres do sensacionalismo exploram "ad limite" a desgraça dessas pessoas e enchem os "media" de todo o tipo de informações e desinformações, não raro numa postura mórbida de sensacionalismo, incluindo o julgamento em praça pública.

Entre nós têm prevalecido exemplos opostos, com "media" sensatos, responsáveis e sensíveis.

É também nestas alturas que emergem altruísmos verdadeiros e heroicos pela entrega que demonstram, como temos visto demonstrado em todo o mundo. A sociedade encontra em si energia e iniciativas de solidariedade que ajudam a mitigar o infortúnio do outro. O cidadão anónimo tem tido um importante papel dinamizador dessas iniciativas a par das 
respostas institucionais dos profissionais de saúde e das forças de segurança.

Os decisores, confrontados com as notícias e sentindo as mesmas fragilidades de todos os outros humanos, tomam decisões divergentes, muitas vezes sem aconselhamento suficiente para fazerem prevalecer a sensatez e a prudência. Contudo, entre nós a ação dos decisores, às vezes a reboque da maré, tem sido resiliente e capaz de corresponder aos desafios.

\section{Saber e aprender, ... há muito que aprender}

Muitos de nós apelam ao conhecimento científico para se balizarem e referenciarem, mas também aqui temos mais a aprender do que referências seguras.

Os epidemiologistas que defendem uma postura face ao COVID-19 comparável à da gripe (disseminar e imunizar) têmse confrontado com avalanches de doentes graves a afluírem ao mesmo tempo aos hospitais que, nessas condições, não têm conseguido dar resposta à procura. É nessas condições, que em alguns ambientes, têm corrido picos de mortalidade dramáticos, ${ }^{7}$ ceifando em particular os mais velhos com comorbilidades múltiplas, o que gera receio, angústia e medo, ... muito medo. São contextos dramáticos. Ninguém fica indiferente às notícias de centenas de mortos por dia associados a esta doença. ${ }^{7}$

Já sabíamos que não conhecíamos tratamento etiológico para este vírus, mas sentimos o conforto de dispor dos recursos e saberes da Medicina Intensiva capazes de suportar doentes em dificuldade respiratória e/ou disfunção órgãos essenciais à vida, como acontece com outras pneumonias víricas. A imagem dos cuidados intensivos e a forma como enfrentam situações extremas atraiu muitos repórteres. A vida e a morte nos cuidados intensivos passaram a primeira página dos noticiários, nem sempre com respeito pela privacidade e dignidade das vítimas. Lemos e ouvimos várias vezes que “... os médicos vivem a opção agonizante de decidir quem vive e quem morre ...". É verdade que há relatos de situações em que houve falta de ventiladores, mas entre nós, no momento em que vos escrevo, não há notícia de que tal tenha acontecido e há mesmo centenas de ventiladores comprados ao exterior por causa desta pandemia que ainda não chegaram a Portugal. Há mais pessoas salvas fora dos Cuidados Intensivos do que nos Cuidados Intensivos. Há mais pessoas salvas pelas medidas de contenção da infeção do que pelo acesso a ventiladores.

O conhecimento que temos sobre o tratamento deste vírus tem uma boa margem de progressão. No início da pandemia acreditávamos que o envolvimento pulmonar do SARS CoV-2 (COVID-19) era idêntico ao ARDS que conhecíamos de situações anteriores. Sabemos hoje que nem sempre é assim e que há formas de envolvimento pulmonar, fortemente hipoxemiantes mesmo antes da exsudação inflamatória caraterística do ARDS clássico. ${ }^{8}$ Estas infeções não são infeções respiratórias, são doença sistémica que na maioria das vezes se apresenta como infeção respiratória. ${ }^{8}$

Perante tais dúvidas e sem tempo para estudos com base na evidência houve quem reabilitasse estratégias antigas que não provaram ser eficientes no passado, na expectativa de que desta vez desse certo. O mesmo aconteceu com os medicamentos antivirais. Na ausência de tratamentos comprovadamente eficazes surgiram propostas de base casuística ou anedótica a par de estudos controlados e com base científica credível. O conhecimento é inseguro, incerto e está em permanente movimento, o que facilitou a ocorrência de propostas que não são justificáveis pelo conhecimento existente, que não são prudentes e que se publicitam com soberba, sem a humildade científica para aceitar o saber consolidado, testado e conhecido. A inovação é premente porque o saber é insuficiente, mas tem de se restringir aos domínios reconhecíveis como investigação controlada com base científica. Não vale testar tudo o que vem á ideia. A última "boca" "tweetada" ou a publicação de autor sem escrutínio interpares, não é uma recomendação de tratamento e muitas vezes não é sequer aceitável como prática médica.

\section{O luto}

A grande maioria dos infetados sobreviveu à infeção, sem sequelas, muitos ficarão imunizados. Mas houve centenas dos nossos que partiram sem se poderem despedir dos que lhe eram significativos e muitos dos que não partiram ficaram sem ter tido oportunidade de se despedirem dos que partiram. NaIguns casos os que partiram foram sepultados em cerimónias breves, ou sem cerimónia, mas demasiadas vezes sem a presença de familiares e amigos.

Muitos mais sobreviveram com um luto perturbado cujas sequelas ainda não conhecemos. Em muitos casos os rituais da despedida não foram respeitados e nalguns casos os corpos foram coercivamente reduzidos a cinzas. Nem todos vamos passar ou passamos por essa experiência incólumes.

\section{O futuro que nos espera}

Os médicos e restantes profissionais de saúde assumiram as suas responsabilidades e lideram a resposta à pandemia com resultados positivos que nos dão o conforto de saber que o nosso sistema de saúde não colapsou. Temos agora que recuperar, cuidar e tratar TAMBÉM de todos os NÃO COVID, que se recolheram, auto confinaram e/ou que deixaram de ter acesso facilitado aos serviços de saúde que se obcecaram com os casos COVID positivos.

As sequelas económicas e sociais desta pandemia abrirão novos capítulos na morbilidade das populações. Cumpre-nos estar atentos e disponíveis para essa frente.

As sequelas económicas e sociais terão consequências que não conhecemos, mas que serão motivo e motor de transformação da organização social, das relações de trabalho e dos modelos de relação médio / doente. Temos também de estar atentos e participar nessa frente. 
Como sustenta Arundhati Roy 9 “... Historicamente, as pandemias forçaram os seres humanos a romper com o passado e a imaginar de novo o seu mundo. Esta não é diferente. É um portal, uma porta de entrada entre um mundo e o seguinte..."

O SARS CoV-2 (COVID-19) continua entre nós e é antecipável que continuemos a conviver com ele, até haver uma vacina eficaz. É tempo de nos ajustarmos a um "novo normal", onde os valores da sociedade e das relações humanas se vão re-escrutinar e reestruturar. Os profissionais ligados à saúde e ao cuidar dos mais vulneráveis, estão em boa posição para se questionar sobre o seu papel na definição desse "novo normal" e dessa forma ser parte da sua construção.

\section{Responsabilidades Éticas}

Conflitos de Interesse: Os autores declaram a inexistência de conflitos de interesse na realização do presente trabalho.

Fontes de Financiamento: Não existiram fontes externas de financiamento para a realização deste artigo.

Proveniência e Revisão por Pares: Comissionado; sem revisão externa por pares.

\section{Ethical Disclosures}

Conflicts of interest: The authors have no conflicts of interest to declare. Financing Support: This work has not received any contribution, grant or scholarship

Confidentiality of Data: The authors declare that they have followed the protocols of their work center on the publication of data from patients.

Provenance and Peer Review: Commissioned; without externally peer reviewed.

(C) Autor (es) (ou seu (s) empregador (es)) 2019. Reutilização permitida de acordo com CC BY-NC. Nenhuma reutilização comercial.

(c) Author(s) (or their employer(s)) 2019. Re-use permitted under CC BYNC. No commercial re-use.
Correspondence / Correspondência:

António H. Carneiro - amhcarneiro@gmail.com

Chefe de Serviço de Medicina Interna, Diretor do Departamento de Medicina, Urgência e UCl, Hospital da Luz - Arrábida, Vila Nova de Gaia, Portugal

Praceta de Henrique Moreira 150, 4400-346 Vila Nova de Gaia

Received / Recebido: 23/4/2020

Accepted / Aceite: 24/04/2020

Publicado / Published: 4 de Maio de 2020

\section{REFERÊNCIAS}

1. Gates Bill. A próxima epidemia? não estamos preparados [acedido Abril 2020] Disponível em: https://www.ted.com/talks/bill_gates_the_next_outbreak_we_re_not_ready?language=pt-br - Ted Talk 2015.

2. Jones, D S. History in a Crisis - Lessons for Covid-19. NEJM March 12, 2020.

3. LePan Richard. Visualizing the History of Pandemics [acedido Abril 2020] Disponível em: https://www.visualcapitalist.com/history-of-pandemics-deadliest/ The visual capitalist. Mach 042020

4. Murthy S, Gomersall CD, Fowler RA. Care for Critically III Patients With COVID-19. JAMA. 2020;323:1499-500. doi:10.1001/jama.2020.3633.

5. Wadman M, Couzin-Frankel J, Kaiser J, Matacic C. How does coronavirus kill? Clinicians trace a ferocious rampage through the body, from brain to toes. Science Apr. 17, 2020 [acedido Abril 2020] Disponível em: https:// www.sciencemag.org/news/2020/04/how-does-coronavirus-kill-clinicians-trace-ferocious-rampage-through-body-brain-toes\#.

6. Francisco, Papa. Homilia de 2020 abril 19 na Basilica de S. Pedro em Roma.

7. Richardson S, Hirsch JS, Narasimhan M, Crawford JM, McGinn T, the Northwell COVID-19 Research Consortium, et al. Presenting Characteristics, Comorbidities, and Outcomes Among 5700 Patients Hospitalized With COVID-19 in the New York City Area. JAMA. 2020 (in press). doi:10.1001/ jama.2020.677.

8. Gattinoni L, Chiumello D, Rossi S. COVID-19 pneumonia: ARDS or not? Critical Care. 2020; 24:154.

9. Roy A. Financial Times, 2020 april 03. [acedido Abril 2020] Disponivel em: 